\title{
Effect of Heart Rate on Coronary Circulation
}

\author{
Kizuku Kuramoto, Hon Ying Lie, Saichi Hosoda, \\ Hiroshi Kurihara, Masao Ikeda and Kiku Nakao
}
The Third Department of Internal Medicine (Prof. K. Nakao), Faculty of Medicine, University of Tokyo, Tokyo

\begin{abstract}
The direct and secondary effects of tachycardia and of bradycardia on the coronary circulation were evaluated in pacing the heart at the rates of 60 to 240 per minute.

In the initial phase of marked tachycardia, there were observed decrease in coronary blood flow and increase in coronary vascular resistance, presumably due to direct mechanical effect of tachycardia on the coronary vasculature. The increases in coronary vaseular resistance were $4.9 \%, 8.5 \%, 26.7 \%$ and $38.8 \%$ at the ventricular rates of $60,120,180$ and 240 , respectively. The coronary blood flow increased in the late phase of marked ventricular tachycardia, suggesting that this might be due to the effect of metabolic and humoral factors. The coronary vascular resistance decreased by $1.0 \%, 12.5 \%, 30.5 \%$ and $32.2 \%$ at the ventricular rates of $60,120,180$ and 240 , respectively. Changes in heart rate from the ventricular trachycardia to the ventricular automatism were considered to reveal the effect of bradycardia. The coronary vascular resistance decreased in bradycardia starting from the ventricular rates of 180 and 240 , and averaged $-15.3 \%$ and $-24.6 \%$, respectively.
\end{abstract}

Coronary circulation is under a complex hemodynamic control along with neurohumoral and metabolic influences. In a preceding paper, ${ }^{1}$ we described that a transient increase in coronary blood flow and decrease in coronary vascular resistance on vagal stimulation was chiefly due to mechanical factors such as bradycardia and cessation of atrial contraction. However, the effect of the heart rate on the coronary circulation has not reached an agreed conclusion. Some authors hold that coronary blood flow increases in bradycardia as well as in tachycardia, while others found decrease in the coronary blood flow. ${ }^{2-10}$ It is conceivable that the changes in heart rate influence the myocardial metabolism and consequently alter the coronary blood flow. The autoregulatory mechanism may participate in the coronary circulation. ${ }^{11}$ To elucidate the effect of the heart rate on the coronary blood flow, it is necessary to separate a direct effect of the heart rate from a secondary effect caused by a metabolic or other regulatory mechanisms. The present study was undertaken to this direction by pacing the heart at the predetermined rates with a pacemaker.

Received for publication, January 5, 1966. 


\section{METHODS}

Five dogs of $10-15 \mathrm{~kg}$ were used. The method for perfusion of the left coronary artery, and the operative procedures for producing $A-V$ block were described in our preceding paper. ${ }^{1}$ To control the heart rate, the left ventricle was stimulated at predetermined rates with a square wave current of 5-10 volts and 5-10 msec in duration. The different electrode was inserted into the epicardium of the upper portion of the anterior septum, indifferent electrode being inserted into the thoracic wall. The heart rate was kept at the rates of $60,120,180$ and 240 per minute for 15 to 20 seconds. As described in our preceding paper, changes in the blood pressure, coronary blood flow and coronary vascular resistance were studied in connection with changes in the heart rate. Each experiment was devided into four phases; the control phase of ventricular automatism (first phase), the initial phase of tachycardia (second phase), late phase (third phase) and the phase of bradycardia of ventricular automatism by stopping the pacemaker (fourth phase). In each phase of tachycardia and bradycardia, the blood pressure and coronary blood flow were read for the calculation within 5 seconds before and after the change of the heart rate. The direct and secondary influences of tachycardia were analyzed by comparing the second and third phases with the first phase; the influence of bradycardia was investigated comparing the fourth phase with the third phase.

\section{RESULTS}

\section{Coronary circulation in response to the change in heart rate}

The changes in the blood pressure, coronary blood flow, and coronary vascular resistance in control phase, initial phase of tachycardia, late phase of tachycardia, and the phase of bradycardia, are shown in Table 1 . The representative tracings (No. 625, Exp. 3-6) are shown in Figs. 1 and 2, and the changes in blood pressure, coronary blood flow, and coronary vascular resistance at the heart rate of $60,120,180$ and 240 are shown in Fig. 3 (No. 620).

Heart rate: The heart rates of ventricular automatism in five dogs were 63 , 45, 40, 38 and 41, and averaged 45. After the heart rate had been increased by electrical stimulation to 60 and 120 per minute, it returned to the previous rate on discontinuance of the stimulation; when the pacemaker was stopped at the rates of 180 and 240 , the heart rate decreased to around two-thirds of the control level for about 10 seconds, and gradually returned to the previous value. This tendency was observed in 3 cases.

Blood pressure: When the heart rate was increased to 60 and 120 , the blood pressure increased by $9.4 \%$ and $16.0 \%$, respectively, and maintained the same levels during the stimulation. The blood pressure returned to the previous level after discontinuance of the stimulation. When heart rate was raised to 180 , a slight fall in blood pressure in the initial phase was observed in 2 cases. At the 


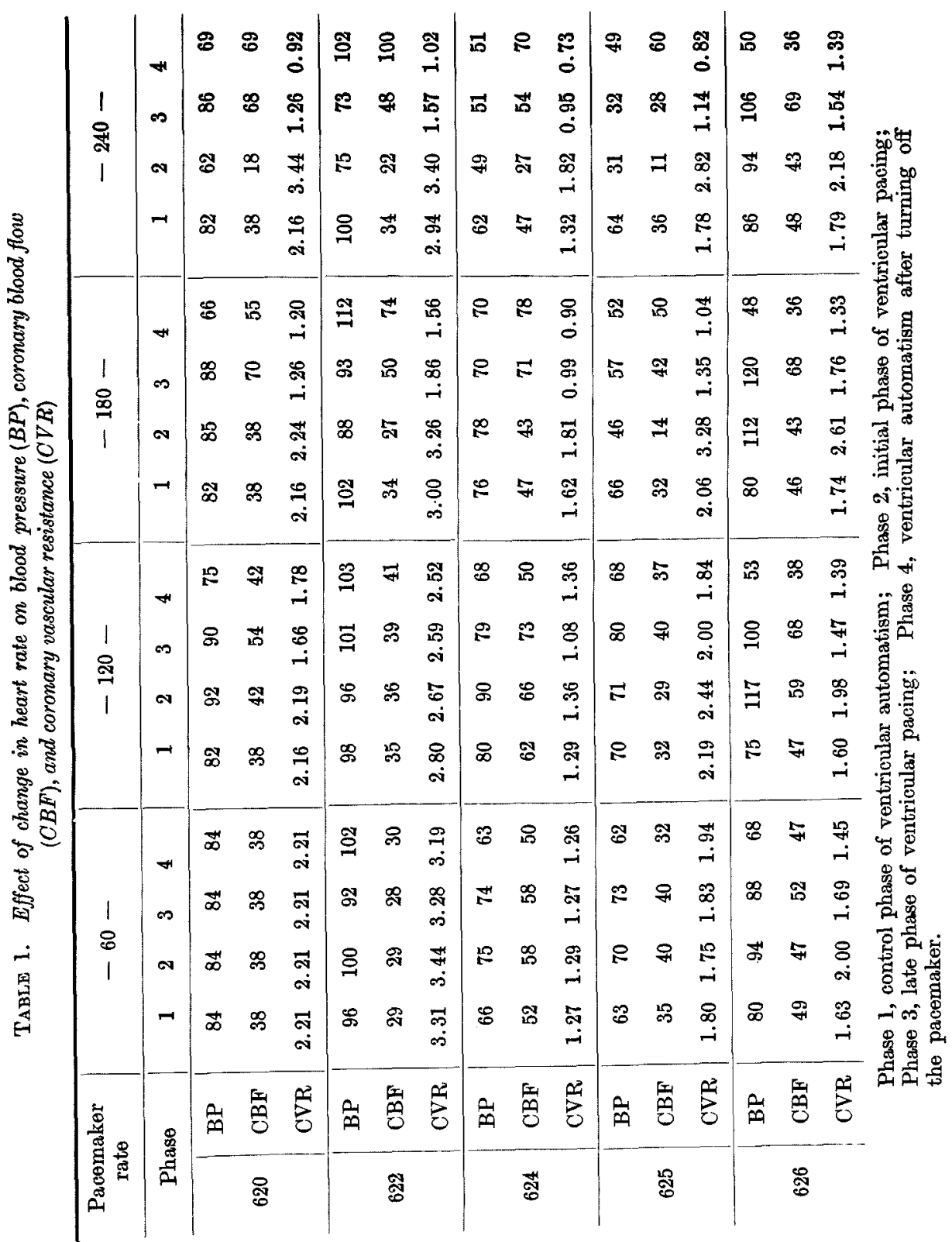

heart rate of 240 , blood pressure decreased $22.5 \%$ on an average in the initial phase, then rose gradually toward the previous level during the tachycardia. At transferring from tachcyardia to bradycardia of ventricular automatism, increase in pulse pressure and in systolic pressure was observed; the change in mean 

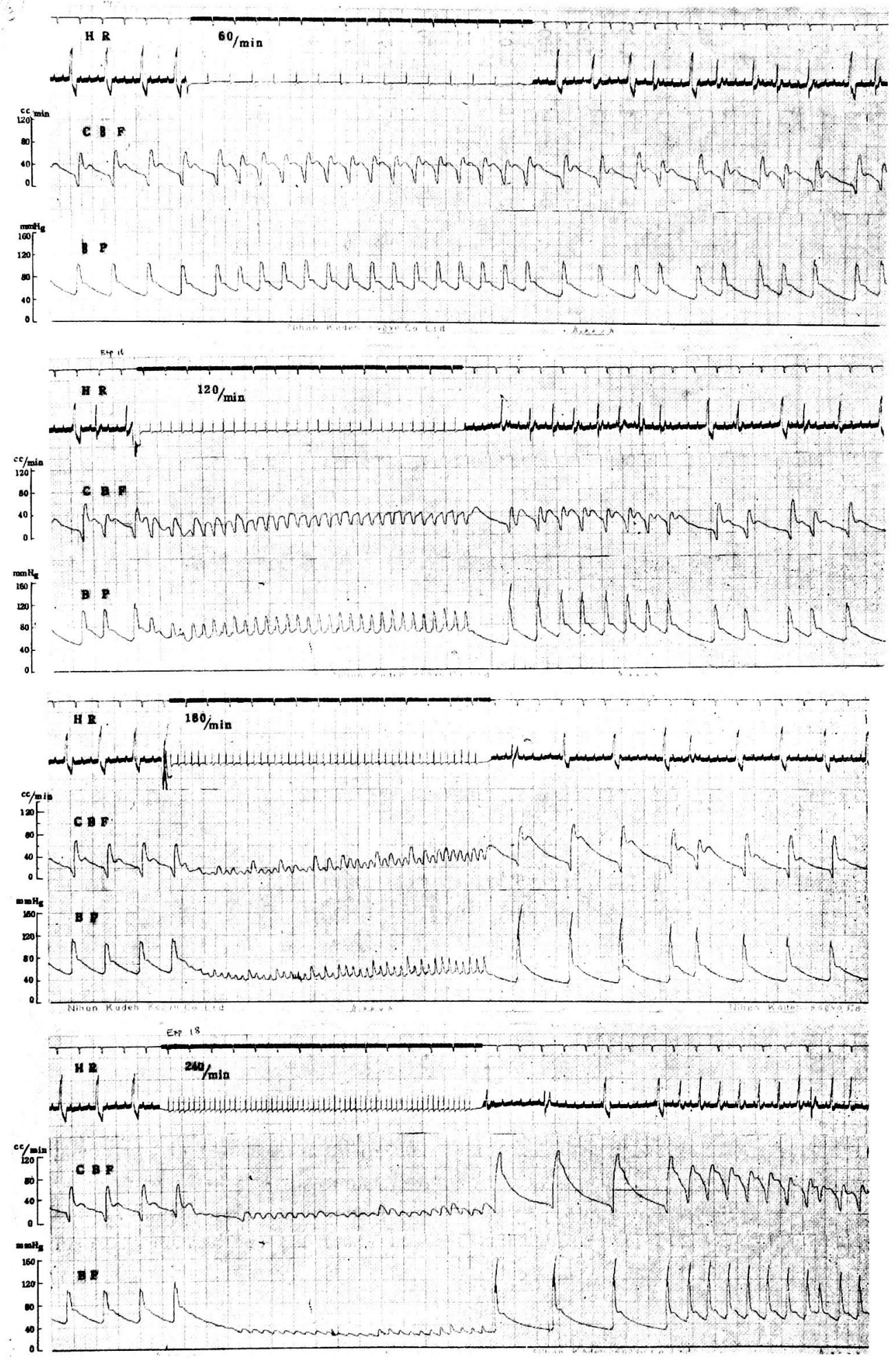

Figs. 1 and 2. Records showing the electrocardiogram (ECG), coronary blood flow (CBF), and blood pressure (BP) at pacemaker rates of $60,120,180$, and 240 per min. Electrocardiogram was attenuated during the pacing of the heart. (Dog 625.) 


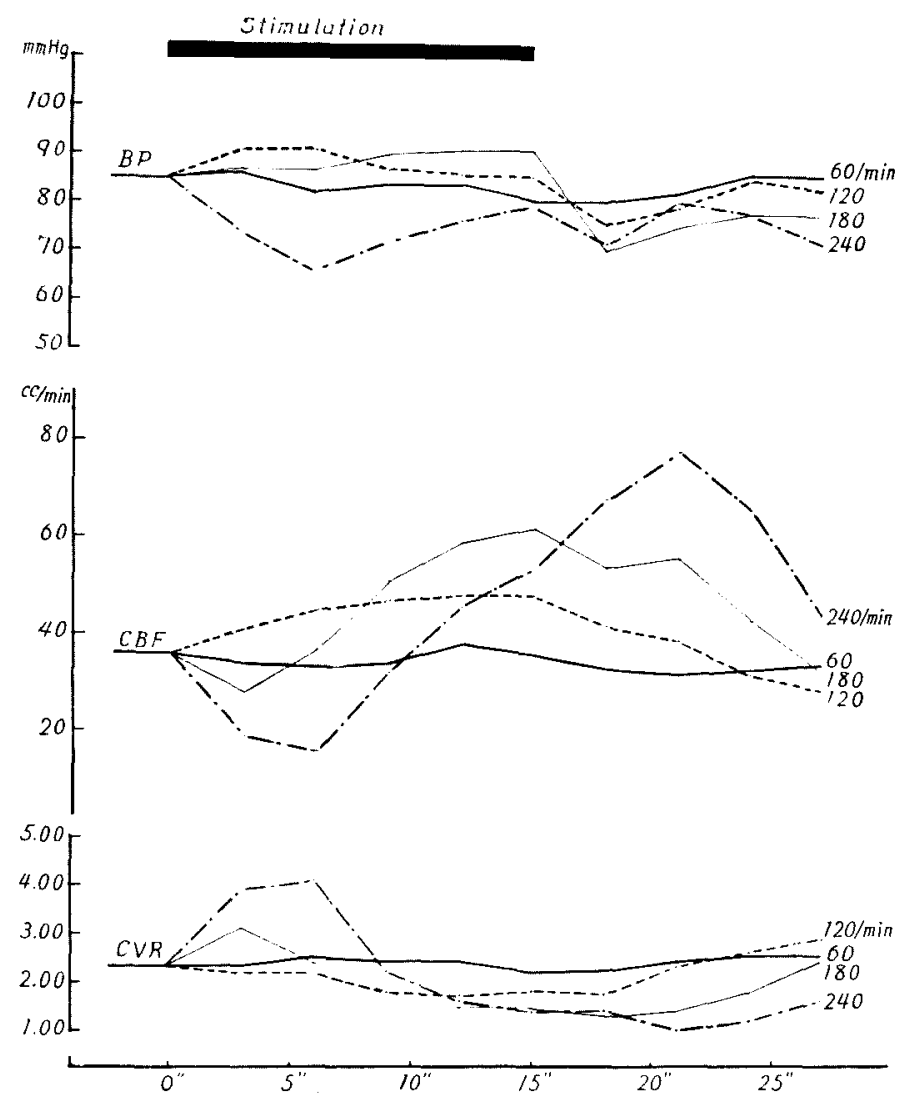

Fig. 3. Schematic drawing of changes in blood pressure (BP), coronary blood flow (CBF), and coronary vascular resistance (CVR) at pacemaker rates of $60,120,180$, and 240. (Dog 620.)

blood pressure was to a slight degree.

Coronary blood flow: The increase in heart rate to 60 and 120 caused an increase of coronary blood flow by $6.0 \%$ and $7.2 \%$ at the initial phase, and by $5.7 \%$ and $28.4 \%$ in the late phase, respectively. When heart rate was increased to 180 and 240 , the coronary blood flow decreased initially to $-18.4 \%$ and $-42.1 \%$ respectively, then it increased markedly in the late phase to $52.3 \%$ and $31.3 \%$ of the control level. Discontinuing the stimulation at the heart rate of 240 , the coronary blood flow further increased by $41 \%$.

2. Effect of heart rate on coronary vascular resistance

Tachycardia: Percentage changes in coronary vascular resistance, when the heart rate was increased from the ventricular automatism to $60,120,180$, and 240 per minute, are shown in Fig. 4. The average increases in the initial phase of tachycardia were $4.9 \%, 8.5 \%, 26.7 \%$, and $38.8 \%$, respectively, showing a marked 
increase at heart rate of over 180 (Table 2). In the late phase of tachycardia, coronary vascular resistance decreased with the increase in heart rate, averaging $1.0 \% .-12.8 \%,-30.5 \%$, and $-33.2 \%$, respectively. A marked decrease was observed in tachycardia over 180 .

Effect of tachycardia

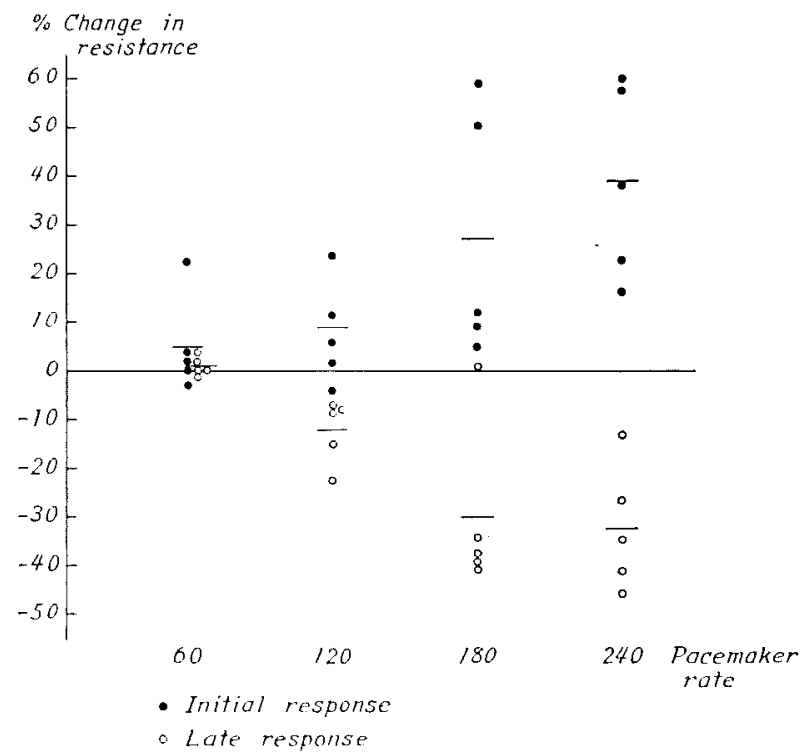

Fig. 4. Effect of tachycardia on the coronary vascular resistance. Ordinate represents percentage change in coronary vascular resistance during tachycardia. Dots indicate the initial responses to tachycardia. Open circles indicate the late response.

TABle 2. Percentage change in coronary vascular resistance in response to tachycardia and bradycardia

\begin{tabular}{|c|c|c|c|c|c|}
\hline \multicolumn{2}{|c|}{ Pacemaker rate } & 60 & 120 & 180 & 240 \\
\hline \multirow{2}{*}{$\begin{array}{l}\text { Tachy- } \\
\text { cardia }\end{array}$} & $\begin{array}{c}\text { Initial } \\
\text { phase }\end{array}$ & 4.9 & 8.5 & 26.7 & 38.8 \\
\hline & $\begin{array}{l}\text { Late } \\
\text { phase }\end{array}$ & 1.0 & -12.8 & -30.5 & -33.2 \\
\hline \multicolumn{2}{|c|}{ Bradycardia } & -2.2 & 3.4 & -15.3 & -24.6 \\
\hline
\end{tabular}

Bradycardia: Effect of bradycardia was investigated by discontinuance of the pacemaker. The average heart rate of ventricular automatism was about 50 . The percentage decrease in heart rate from 60, 120, 180 and 240 to ventricular automatism were $19.7 \%, 53.6 \%, 70.3 \%$ and $75.0 \%$; the changes in coronary vascular resistance were $-2.2 \%,+3.4 \%,-15.3 \%$ and $-24.6 \%$, repectively. A 


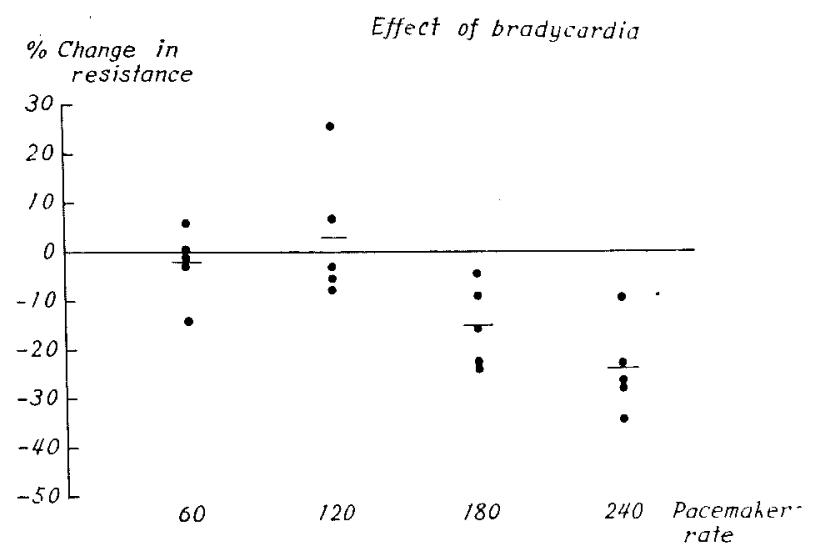

Fig. 5. Effect of bradycardia on the coronary vascular resistance. Ordinate represents percentage change in coronary vascular resistance during ventricular automatism which has been transferred from various pacemaker rates.

remarkable decrease in coronary vascular resistance was observed in bradycardia starting from 180 and 240 (Fig. 4 ; Table 2).

\section{DISCUSSION}

The present study revealed that the decrease in coronary blood flow and the increase in coronary vascular resistance in the initial phase of tachycardia might be due to the direct mechanical effect, while the increase in coronary blood flow and decrease in coronary vascular resistance in the late phase might be due to the effect of humoral and metabolic factors.

Anrep ${ }^{2}$ and Gregg, ${ }^{3}$ put forward the view that in tachycardia the coronary blood flow decreased by shortening of diastole and strengthening of contraction. On the other hand, Laurent et al., ${ }^{5}$ Berglund et al., ${ }^{6}$ Duff et al. ${ }^{8}$ found that the tachycardia increased coronary blood flow and myocardial oxygen consumption associated with the work of the heart. These two opposed results were observed in the present experiments as initial and late responses to tachycardia. In the initial phase of tachycardia of up to 120 in heart rate, the blood pressure and coronary blood flow increased slightly with a slight change in coronary vascular resistance. Berglund et al. ${ }^{6}$ described that cardiac output of the dog was at the highest level when the heart rate was between 120 and 180 . The blood pressure in our experiments revealed a similar response. The mechanism of the decrease in coronary blood flow and increase in coronary vascular resistance at the heart rate of over 180 might be considered to be due to the mechanical compression of the coronary vascular bed by tachycardia. The increase in coronary blood flow was observed in the late phase of tachycardia. Berglund et al. ${ }^{6}$ observed that when heart rate was increased with pacemaker from 60 to 240 , a marked increase in 
coronary blood flow despite the decrease in cardiac output and blood pressure; the coronary vascular resistance at the heart rate of 230 decreased to a half of the value at 60 . Laurent et $a .^{5}$ also observed increase in myocardial oxygen consumption and in coronary blood flow in parallel with increase in heart rate; they inferred that the myocardial oxygen consumption might be controlled so as to maintain a certain level of oxygen tension in the myocardium. Gorlin, injected atropine to 6 patients, and found increase in coronary blood flow by $38 \%$ with increase in heart rate by $38 \%$ on an average, showing the relations between the myocardial oxygen consumption and the duration of systole. Wegria et al. ${ }^{7}$ found that the increase in heart rate by 20 per minute in sinus rhythm caused a slight change; the increase by 30 per minute caused decrease in cardiac output and blood pressure followed by a gradual return to the previous values, while the coronary blood flow decreased initially, and then increased remarkably over the control level. The increase in heart rate to about 200 by increasing 30 per minute from sinus rhythm of 140-190 revealed the same tendency as in our experiments, where heart rate was increased from 45 to 180-240. This shows that the circulatory dynamics is regulated rather by the absolute rate of the heart than by its changing rate.

A close correlation of the coronary blood flow or myocardial oxygen consumption with the cardiac work was recognized by Gregg, ${ }^{3}$ Katz et al. ${ }^{12}$ and Feinberg $e t$ al. $^{13}$ Thus, the heart has an autoregulatory function to cardiac work and metabolic demand. Rosenblueth et al. ${ }^{14}$ stated that if the heart rate and blood pressure were in a fixed level, the change in the cardiac work did not alter the coronary blood flow. Sarnoff, et al., ${ }^{15}$ and Rodbord et al. ${ }^{16,17}$ found a close relationship between the myocardial tension and coronary blood flow or myocardial oxygen consumption. Sarnoff et al. proposed tension time index. Rodbord et al. calculated the myocardial tension from blood pressure and cardiac output by using Laplace's law. It seems very likely that increase in coronary blood flow during a marked tachycardia is brought about by increase in the myocardial tension and by metabolic factors. Murata ${ }^{18}$ found a vasodilator substance in the coronary sinus blood following cardiac sympathetic stimulation. Nakano et al. ${ }^{19,20}$ found that lowering of the blood pressure and pulse pressure in tachycardia stimulated the sympathetic nervous system and increased the catecholamine level in blood. The humoral regulation of coronary circulation may be an essential factor for increasing the coronary blood flow in the late phase of tachycardia.

The transient increase in coronary blood flow during the bradycardia or cardiac arrest has been attributed to the decrease in extravascular pressure and to the prolonged diastole. Lewis et al. ${ }^{10}$ controlled the heart rate with pacemaker and found that a cardiac arrest by turning off the pacemaker increased the coronary blood flow; cardiac arrest starting from the heart rate of 90 to 150 
increased coronary flow by $40 \%$, while cardiac arrest from heart rate of 180 and 240 caused the increase by $47 \%$ and $56 \%$, respectively. The present results showed that the coronary blood flow decreased in bradycardia starting from 60 and 120 to the heart rate of ventricular automatism, but coronary vascular resistance was unchanged. In bradycardia starting from 240 the coronary blood flow increased by $41 \%$, and coronary vascular resistance decreased by $33 \%$. Since the effect of bradycardia in the present study was investigated after blood pressure and coronary blood flow had reached a plateau level in tachycardia, and the interval between the late phase of tachycardia and the phase of bradycardia was only several seconds, the effect of humoral factors was considered to be similar in both phases. A reactive hyperemia in coronary circulation may be a cause of the increase in coronary blood flow in bradycardia transferred from a marked tachycardia. Coffman and Gregg ${ }^{21}$ observed the overpayment of the oxygen debt following the coronary occlusion for 5 seconds to 2 minutes. Rein ${ }^{22}$ also presented similar results. It is conceivable that a mechanism of reactive hyperemia may play a role when oxygen lack caused by mechanical compression in tachycardia may be removed by decreasing the heart rate.

\section{SUMMARY}

The direct and secondary effects of tachycardia on the coronary circulation were analyzed in the dog's heart with atrioventricular block, pacing the heart at rates of $60,120,180$ and 240 per minute from ventricular automatism (heart rate 45 on an average). The effect of bradycardia was also studied by turning off the pacemaker from various heart rates.

1. In the initial phase of marked tachycardia, a decrease in coronary blood flow and an increase in coronary vascular resistance were observed, presumably due to direct mechanical effect of tachycardia on the coronary vasculature. Increases in coronary vascular resistance were $4.9 \%, 8.5 \%, 26.7 \%$ and $38.8 \%$ at ventricular rates of $60,120,180$ and 240 , respectively.

2. The coronary blood flow increased in the late phase of marked ventricular tachycardia. This suggested the effect of metabolic and humoral factors. The coronary vascular resistance decreased by $1.0 \%, 12.5 \%, 30.5 \%$ and $32.2 \%$ at the pacemaker rates of $60,120,180$ and 240 , respectively.

3. Changes in heart rate from ventricular tachycardia to the ventricular automatism were considered to reveal the effect of bradycardia. The coronary vascular resistance remained unchanged in bradycardia starting from ventricular rates of 60 and 120 , but it decreased in bradycardia from ventricular rates of 180 and 240 , and averaged $-15.3 \%$ and $-24.6 \%$, respectively.

\section{References}

1) Nakao, K., Ikeda, M., Kuramoto, K., Lie, H.Y., Hosoda, S., Kurihara, H., Murata, K., Kimata, S. \& Ozawa, T. Effect of efferent vagal stimulation on coronary circulation 
in atrioventricular block. Tohoku J. exp. Med., 1966, 88, 221-234.

2) Anrep, G.V. The regulation of the coronary circulation. Physiol. Rev., 1926, 6, 596629.

3) Gregg, D.E. Coronary circulation in health and disease. Lee \& Febiger, Philadelphia, 1950.

4) Gorlin, R. Studies on the regulation of the coronary circulation in man. 1. Atropine-induced changes in cardiac rate. Amer. J. Med., 1958, 25, 37-42.

5) Laurent, D., Bolene-Williams, C., Williams, F.L. \& Katz, L.N. Effects of heart rate on coronary flow and cardiac oxygen consumption. Amer. J. Physiol., 1956, 185, 355-364.

6) Berglund, E., Borst, H.G., Duff, F. \& Schreiner, G.L. Effect of heart rate on cardiac work, myocardial oxygen consumption and coronary blood flow in the dog. Acta physiol. scand., 1958, 42, 185-198.

7) Wegria, R., Frank, C.W., Wang, H.H. \& Lammerant, J. The effect of atrial and ventricular trachycardia on cardiac output, coronary blood flow and mean arterial blood pressure. Circulat. Res., 1958, 6, 624-632.

8) Duff, F., Berglund, E. \& Borst, H. Effect of heart rate on ventricular function and coronary circulation in dogs. Amer. J. Physiol., 1955, 183, 611.

9) Berglund, E., Monroe, R.G. \& Schreiner, G.L. Myocardial oxygen consumption and coronary blood flow during potassium induced cardiac arrest and during ventricular fibrillation. Acta physiol. scand., 1957, 41, 261-268.

10) Lewis, F.B., Coffman, J.D. \& Gregg, D.E. Effect of heart rate and intracoronary isoproterenol, levarterenol, and epinephrine on coronary flow and resistance. Circulat. Res., 1961, 9, 89-95.

11) Mosher, P., Ross, J., MeFate, P.A. \& Shaw, R.F. Control of coronary blood flow by an autoregulatory meohanism. Circulat. Res., 1964, 14, 250-259.

12) Katz, A.M., Katz, L.N. \& Williams, F.L. Regulation of coronary flow. Amer. J. Physiol., 1955, 180, 392-402.

13) Feinberg, H., Katz, L.N. \& Boyd, E. Determinants of coronary flow and myocardial oxygen consumption. Amer. J. Physiol., 1962, 202, 45-52.

14) Rosenblueth, A., Alanis, J., Rubis, R. \& Pilar, G. Relations between coronary flow and work of the heart. Amer. J. Physiol., 1961, 200, 243-246.

15) Sarnoff, S.J., Braunwald, E., Welch, G.H., Case, R.B., Stainsby, W.N. \& Macruz, R. Hemodynamic determinants of oxygen consumption of the heart with special reference to the tension time index. Amer.J. Physiol., 1958, 192, 148-156.

16) Rodbard, S., Williams, F. \& Williams, C. The spherical dynamics of the heart (myocardial tension, oxygen consumption, coronary blood flow and efficieny). Amer. Heart J., 1959, 57, 348-360.

17) Rodbard, S., Williams, C.B., Rodbard, D. \& Berglund, E. Myocardial tension and oxygen uptake. Circulat. Res., 1964, 14, 139-149.

18) Murata, K. Studies on the neurohumoral control of the coronary circulation: Coronary vasodilatative substance demonstrated in coronary venous blood samples obtained after the stimulation of the sympathetic nerve. Jap. Circulat. J., 1959, 22, 910-916.

19) Nakano, J. Effects of atrial and ventricular tachycardias on the cardiovascular dynamies. Amer. J. Physiol, 1964, 206, 547-552.

20) Nakano, J. Zekert, H., Griege, C.W., Wang, K.M., Schaefer, H.S. \& Wegria, R. Effect of ventricular tachycardia and arteriovenous fistula on catecholamines blood level. Amer. J. Physiol., 1961, 200, 413-416.

21) Coffman, J.D. \& Gregg, D.E. Reactive hyperemia characteristics of the myocardium. Amer. J. Physiol., 1960, 199, 1143-1149.

22) Rein, H. Úber die Drosselungstoleranz und die kritische Drosselungsgrenze der Herz-Coronargefässe. Pflïgers Arch. ges. Physiol., 1951, 253, 205-223. 